\title{
Analisa Peningkatan Nilai Net Plant Heat Rate (NPHR) pada Unit 1 PLTU Tenayan 2 x 110 MW
}

Yolnasdi, Simson Alfonso Nainggolan

Program Studi Teknik Elektro Sekolah Tinggi Teknologi Pekanbaru

Jl. Dirgantara No.4, Kel, Sidomulyo Tim., Kec. Marpoyan Damai, Kota Pekanbaru, Riau 28125

Email: Yolnasdi9@gmail.com

\begin{abstract}
The Net Plant Heat Rate (NPHR) is an indicator of the reliability and efficiency of a thermal generator, especially a steam power plant. The smaller the NPHR value, the more efficient the power plant is declared and vice versa. There are 3 main parameters that indicate changes in the NPHR value of a PLTU, namely the net load supplied by the PLTU, the amount of coal consumption and the calorific value of coal. The greater the net load distributed by the PLTU to the network, the NPHR value will be smaller or better.

In monitoring the NPHR of PLTU UBJOM Tenayan unit 1 using the input-output method calculation, there are indications of an increase in the NPHR value which is directly proportional to the increase in the value of the auxiliary power. The increasing value of auxiliary power is closely related to the net load generated by the PLTU to the network. In this study, the solution was solved by performing a performance test to obtain the data needed in calculating the NPHR with the heat loss method. Calculations using the heat loss method have the advantage of classifying factors that cause an increase in NPHR. By knowing the factors of these losses, the root cause of failure can be found and the preparation of the planned failure defense task is more accurate.

From the results of the research conducted, auxiliary power is the largest contributor to the NPHR value which is included in the plant controllable category. Through the preparation of Paretobased auxiliary power management that has been carried out, it was found 5 main auxiliary equipment namely SA Fan, BFP, Condensate Pump, CWP and cooling fan which became the source of the cause of the increase in main auxiliary power by $2 \%$ and the impact on losses of $55.16 \mathrm{kCal} \mathrm{kWh}$ and loss production of $R p$. 24,602,765.81 per day.
\end{abstract}

Keywords: NPHR, auxiliary power, auxiliary power management, root cause failure, failure defense task, pareto

\section{Abstrak}

Net Plant Heat Rate (NPHR) merupakan indikator kehandalan dan efisiennya sebuah pembangkit thermal khususnya PLTU. Semakin kecil nilai NPHR maka PLTU dinyatakan semakin efisien dan sebaliknya. Terdapat 3 parameter utama yang menunjukkan indikasi perubahan nilai NPHR suatu PLTU yaitu beban (load) neto yang disuplai oleh PLTU, jumlah konsumsi batubara dan nilai kalori batubara. Semakin besar beban neto yang disalurkan PLTU ke jaringan, maka nilai NPHR akan semakin kecil atau bagus.

Dalam monitoring NPHR PLTU UBJOM Tenayan unit 1 menggunakan perhitungan metode input-output terdapat indikasi peningkatan nilai NPHR yang berbanding lurus dengan meningkatnya nilai auxiliary power. Meningkatnya nilai auxiliary power berkaitan erat dengan beban neto yang dihasilkan oleh PLTU ke jaringan. Pada penelitian ini dilakukan pemecahan solusi dengan melakukan performance test untuk mendapatkan data yang dibutuhkan dalam perhitungan NPHR metode heat loss. Perhitungan dengan metode heat loss memiliki keunggulan untuk mengklasifikasi faktor yang menyebabkan peningkatan NPHR. Dengan mengetahui faktor losses tersebut, root cause failure dapat ditemukan dan penyusunan failure defense task yang direncanakan semakin akurat.

Dari hasil penelitian yang dilakukan, auxiliary power merupakan penyumbang nilai NPHR terbesar yang masuk dalam kategori plant controllable. Melalui penyusunan managemen auxiliary power berbasis pareto yang telah dilakukan, ditemukan 5 peralatan main auxiliary yaitu SA Fan, BFP, Condensate Pump, CWP dan cooling fan yang menjadi sumber penyebab meningkatnya main auxiliary power sebesar $2 \%$ dan berdampak pada losses sebesar 55,16 kCal/kWh serta loss production sebesar Rp. 24,602,765.81 per-hari. 
Kata kunci : NPHR, auxiliary power, managemen auxiliary power, root cause failure, failure defense task, pareto

\section{Pendahuluan}

PLTU Tenayan merupakan pembangkit yang memanfaatkan energi kinetic dari uap untuk menghasilkan energi listrik. PLTU Tenayan yang berlokasi di Kota Pekanbaru merupakan pembangkit listrik yang berada pada system Transmisi SBST (Sumatera Bagian Selatan dan Tengah). PLTU Tenayan memiliki kapasitas sebesar $2 \mathrm{x}$ $110 \mathrm{MW}$ dan menyumbang energi listrik pada Provinsi Riau sebesar $27.6 \%$ dari $651 \mathrm{MW}$ listrik yang dibutuhkan pada Provinsi Riau

Performa suatu pembangkit diukur berdasarkan suatu nilai yang disebut NPHR. Net plant heat rate (NPHR) merupakan nilai yang merepresentasikan jumlah energi yang digunakan untuk menghasilkan energi listrik oleh generator. Semakin besar nilai NPHR yang dihasilkan maka performa pembangkit dinyatakan semakin menurun. Hal tersebut disebabkan karena semakin besarnya energi yang digunakan tetapi energi listrik yang dihasilkan tetap atau semakin kecil.

Salah satu faktor yang dapat menyebabkan meningkatnya NPHR adalah auxilliry power pembangkit yang semakin tinggi. Auxiliary power merupakan daya atau power yang dikonsumsi oleh peralatan listrik yang digunakan untuk proses produksi listrik pada PLTU. Auxiliary power menggunakan output generator sebesar 13 $\mathrm{kV}$ yang mengalami proses step down menggunakan trafo UAT (Unit Auxiliary Trafo) sehingga bisa digunakan sebagai sumber listrik peralatan $6 \mathrm{kV}$ dan $380 \mathrm{~V}$ pada proses produksi. Idealnya nilai auxiliary power pada PLTU sebesar $11 \%$ dari daya yang dihasilkan oleh generator.

Meningkatnya nilai auxiliary power menyebabkan daya yang disuplai pada jaringan menjadi berkurang. Dengan kapasitas PLTU Tenayan 2 x $110 \mathrm{MW}$, maka nilai auxiliary power sebesar $12,5 \mathrm{MW}$ saat unit beroperasi pada beban penuh. Berdasarkan keadaan actual di lapangan saat, terjadi peningkatan nilai auxiliary power sebesar 12,7 MW dengan daya gross yang dihasilkan oleh generator sebesar 98 MW. Dengan adanya kejadian ini, daya listrik yang disuplai oleh generator ke jaringan menjadi turun menjadi $85 \mathrm{MW}$ daya netto dan menyebabkan meningkatnya nilai NPHR sebesar $2 \%$ dari kenaikan nilai NPHR. Peralatan unit auxiliary power memiliki peranan penting bagi proses produksi pembangkit thermal. Adanya kendala yang terjadi pada peralatan unit auxiliary power menyebabkan terganggunya proses produksi listrik yang disuplai pada jaringan atau yang kerap disebut sebagai derating unit.

Meningkatnya auxiliary power sebesar $1 \%$ akan menyumbang $1 \%$ peningkatan NPHR (standard EPRI Heat Rate Guidelines, 1998). Mesin - mesin pembangkit memiliki kapasitas yang berbeda sehingga perlu direncanakan seoptimal mungkin agar diperoleh biaya bahan bakar yang hemat namun mutu dan keandalan tetap terjaga [1]

Motor berfasa banyak adalah motor arus bolak balik (AC) yang direncanakan baik untuk tiga fasa maupun lainnya. Besarnya konsumsi daya yang dimiliki oleh peralatan listrik disebabkan karena adanya pembebanan yang semakin besar atau semakin menurunnya performa motor listrik. Auxiliary power merupakan salah satu faktor yang sangat berpengaruh bagi nilai NPHR sehingga menjadi salah satu concern yang selalu diperhatikan saat komisioning pembangkit listrik.

Tegangan, current, $\cos \phi$, MW dan MVAR adalah parameter yang diamati untuk mengetahui performa motor. Meningkatnya konsumsi daya motor listrik dapat dipengaruhi oleh faktor eksternal seperti lingkungan, beban, frekuensi jaringan dan faktor internal seperti temperature winding motor dan fungsi mechanical pada motor bermasalah. Bertambahnya beban akan memperbesar kopel motor, yang oleh karenanya akan memperbesar arus induksi pada rotor, sehingga slip antara medan putar stator dan putaran rotor pun akan bertambah besar [2]

Net plant heat rate merupakan sebuah parameter yang menunjukkan kinerja suatu pembangkit. NPHR adalah besaran energi yang digunakan untuk menghasilkan daya listrik yang disuplai oleh pembangkit. Semakin besar nilai NPHR yang dihasilkan oleh seuatu pembangkit thermal menunjukkan bahwa efisiensi pembangkit tersebut menurun dan sebaliknya.

Berdasarkan standar yang digunakan (ASME PTC-2008), metode untuk menghitung NPHR dilakukan dengan 2 cara yaitu:

\section{- $\quad$ Metode input - output}

- Metode heat loss

Metode input-output merupakan metode perhitungan dengan memonitoring nilai kalori batubara yang digunakan, jumlah konsumsi batubara dan besarnya daya yang disuplai ke jaringan transmisi. Semakin besar listrik yang diproduksi, maka NPHR akan semakin kecil dan sebaliknya. Hal itu disebabkan karena penggunaan bahan bakar yang semakin ideal meskipun konsumsinya lebih besar dibandingkan saat beban rendah.[3]

Motor induksi merupakan perangkat elektromagnetik yang mengubah energi listrik menjadi energi mekanik. Berputarnya rotor pada motor induksi disebabkan karena adanya gaya gerak listrik (ggl) yang dihasilkan oleh listrik yang masuk pada stator motor. [4] 


\section{Methodologi}

Performa suatu pembangkit thermal dilihat dari seberapa besar energi yang digunakan untuk menghasilkan daya listrik. Semakin besar daya yang diproduksi oleh generator dengan energi yang kecil, maka pembangkit tersebut dinyatakan semakin efisien. Pada pembangkit thermal, indicator yang menyatakan performa / efisiensi pembangkit disebut dengan NPHR (Net Plant Heat Rate).

Berdasarkan konsep manajemen efisiensi, ruang lingkup ini meliputi pengumpulan data, pengolahan data, dan analisa serta reporting seperti yang ada pada gambar 1.1 .

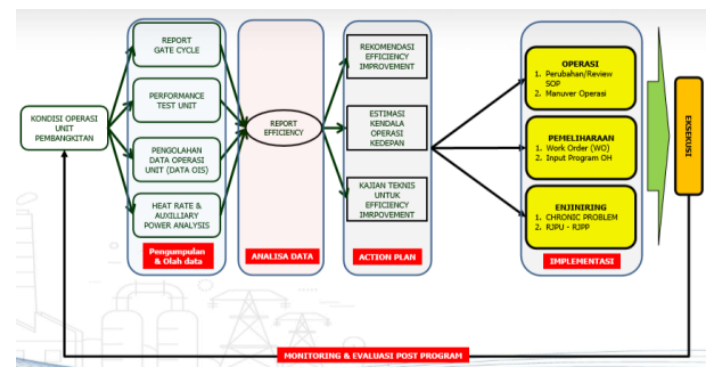

Gambar 1. Workflow efisiensi manajemen

Dalam penelitian ini, pengumpulan data dilakukan dengan 2 metode yaitu pengumpulan data yang dilakukan setiap hari dengan metode perhitungan NPHR input-output dan pengumpulan data bulanan dengan melakukan collecting data unit secara keseluruhan dengan melakukan performance test unit untuk menghitung selisih rugi-rugi NPHR dengan metode heatloss. Berikut bagan alir metode pengumpulan data NPHR.

NPHR merupakan sebuah indikator yang menyatakan baik / buruknya suatu pembangkit thermal. Semakin besar NPHR yang dimiliki menunjukkan bahwa daya suplai terhadap jaringan menurun. PLTU Tenayan merupakan pembangkit thermal yang menggunakan batubara low rank sebagai bahan bakar utama.

Pengujian menggunakan metode input-output bertujuan untuk mengetahui efisiensi unit dengan membandingkan energi listrik output (bruto dan neto) yang diproduksi dengan energi bahan bakar yang digunakan dan dilakukan dengan kondisi parameter unit beroperasi normal.

Pengujian menggunakan metode ini bersiflat daily routine dengan menggunakan parameter acuan sebagai berikut:

\section{- $\quad$ Kwh bruto}

- Kwh neto

- Kwh auxiliary power

- Counter bahan bakar

\subsubsection{Performance test unit}

Performance test merupakan pengujian yang dilakukan untuk mendapatkan data performa unit secara keseluruhan yang diolah menggunakan perhitungan metode NPHR heatloss. Pengujian NPHR menggunakan metode heat loss bertujuan untuk mengetahui efisiensi unit dan memetakan kerugian - kerugian yang terjadi dan dilakukan dengan kondisi parameter operasi unit normal.

Lingkup pengujian PLTU meliputi:

- Boiler

- Turbine

- Auxiliary power

- Sampel bahan bakar

- Sampel debu sisi pembakaran

- Sampel gas buang

Pengambilan data parameter operasi dilakukan menggunakan data logger pada computer DCS dan manual dengan durasi pengambilan data setiap 30 menit selama 4 jam dengan daya output generator konstan dan tidak dilakukan manuver peralatan. Jika terjadi perubahan manuver pengoperasian dengan perbedaan parameter operasi $10 \%$ dari sebelumnya, maka pengujian dianggap gagal.

\section{Hasil dan Pembahasan}

\section{Kondisi Operasi Unit 1 PLTU Tenayan}

Produksi listrik PLTU Tenayan dipengaruhi oleh jumlah bahan bakar yang digunakan dalam menghasilkan daya listrik untuk disalurkan menuju jaringan transmisi. Dalam melakukan monitoring kondisi operasi unit, diperlukan beberapa parameter yang mewakili kesiapan pembangkit dalam beroperasi yaitu daya bruto, daya neto, konsumsi auxiliary power dan konsumsi batubara.

Rekap parameter tersebut dilakukan setiap 24 jam secara kumulatif mulai pukul 00.00 WIB sampai 24.00 WIB. Monitoring parameter tersebut di-input dalam laporan produksi harian yang menjadi dasar monitoring NPHR harian. Berikut data monitoring hasil produksi unit 1 PLTU Tenayan:

Tabel 3.1.Monitoring produksi unit 1 PLTU Tenayan

\begin{tabular}{|c|c|c|c|c|}
\hline TANGGAL & $\begin{array}{c}\text { KWH } \\
\text { BRUTO }(P \\
\text { bruto) } \\
(M W H) \\
\end{array}$ & $\begin{array}{c}\text { KWH } \\
\text { NETO } \\
(P \text { netto }) \\
(\text { MWH }) \\
\end{array}$ & $\begin{array}{c}\text { AUXILIARY } \\
\text { POWER } \\
(M W H)\end{array}$ & $\begin{array}{r}\text { COAL } \\
\text { FLOW } \\
\text { (TON/HA }\end{array}$ \\
\hline 1-Aug-20 & 1939,7 & 1651,35 & 288,35 & \\
\hline 2-Aug-20 & 1985,55 & 1714,27 & 271,285 & 16 \\
\hline
\end{tabular}




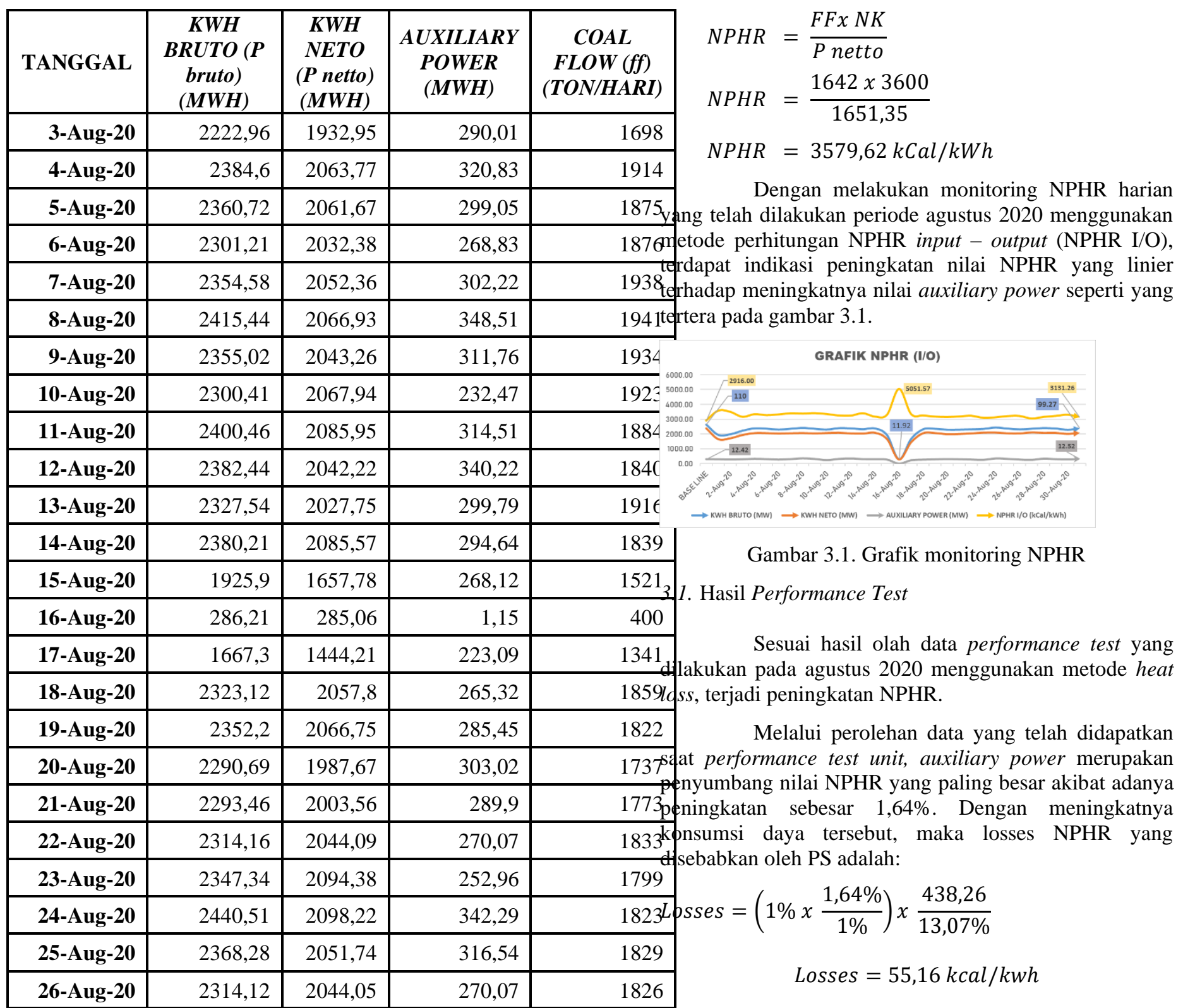

Dari hasil perhitungan NPHR heat loss, break

\begin{tabular}{|r|r|r|r|r|}
\hline 27-Aug-20 & 2357,21 & 2106,38 & 250,83 & 1783 \\
\hline 28-Aug-20 & 2407,99 & 2076,47 & 331,52 & $1820 d$ \\
\hline 29-Aug-20 & 2372,49 & 2077,66 & 294,83 & $1859^{\text {s9 }}$ \\
\hline 30-Aug-20 & 2286,67 & 2008,79 & 277,88 & 1842 \\
\hline 31-Aug-20 & 2382,69 & 2082,1 & 300,59 & 1811 \\
\hline
\end{tabular}

Dalam melakukan monitoring NPHR harian pembangkit, dibutuhkan data hasil produksi dan konsumsi batubara yang dilakukan selama 24 jam dengan kalori (NK) rata-rata batubara adalah $3600 \mathrm{kCal} / \mathrm{kg}$. Dengan menggunakan rumus NPHR i/o seperti yang tertera pada bab 2, maka data NPHR dapat dihitung seperti yang tertera pada tabel 4.2 di bawah ini:

Gambar 3.2. . Grafik NPHR heat loss PLTU Tenayan 
Berdasarkan hasil monitoring dan pengujian NPHR, maka didapatkan resume sebagai berikut:

Tabel 3.2. Resume NPHR

\begin{tabular}{|c|c|c|c|c|c|}
\hline $\mathbf{N}$ & Items & Unit & $\begin{array}{c}\text { Referen } \\
\text { si }\end{array}$ & $\begin{array}{c}\text { Aktu } \\
\text { al }\end{array}$ & $\begin{array}{c}\text { Defisa } \\
\text { si }\end{array}$ \\
\hline 1 & $\begin{array}{l}\text { Daya } \\
\text { Brutto }\end{array}$ & MW & 111,82 & 98,15 & $-13,67$ \\
\hline 2 & $\begin{array}{l}\text { Daya } \\
\text { Netto }\end{array}$ & MW & 99,4 & 85,64 & $-13,76$ \\
\hline 3 & $\begin{array}{l}\text { Pemakaia } \\
\text { n Sendisi } \\
\text { (PS) }\end{array}$ & MW & 12,42 & 12,52 & 0.1 \\
\hline 4 & $\begin{array}{l}\text { Pemakaia } \\
\text { n Sendiri } \\
\text { (PS) }\end{array}$ & $\%$ & 11,11 & 12,75 & 1,64 \\
\hline 5 & $\begin{array}{l}\text { NPHR } \\
\text { heat loss }\end{array}$ & $\begin{array}{c}\mathrm{kCal} / \mathrm{kW} \\
\mathrm{h}\end{array}$ & 2916 & 3354 & 438 \\
\hline 6 & $\begin{array}{l}\text { NPHR } \\
\text { input- } \\
\text { output }\end{array}$ & $\begin{array}{c}\mathrm{kCal} / \mathrm{kW} \\
\mathrm{h}\end{array}$ & 2916 & 3378 & 462 \\
\hline
\end{tabular}

\subsection{Auxiliary Power}

Mengambil data auxiliary power merupakan salah satu scope wajib yang ada saat melakukan performance test. Berdasarkan data yang telah diambil saat melakukan performance test unit, terdapat beberapa peralatan yang telah mengalami kelebihan konsumsi daya dengan melakukan perhitungan seperti yang tertera pada tabel 4.5 di bawah ini:

GAP POWER = MW Agustus $2020-$ POWER $(M W)$ GAP POWER circulating water $p u=0,869-0,886$ GAP POWER circulating water pump $=0,010 \mathrm{MW}$

Tabel 3.3 Break down unit auxiliary power

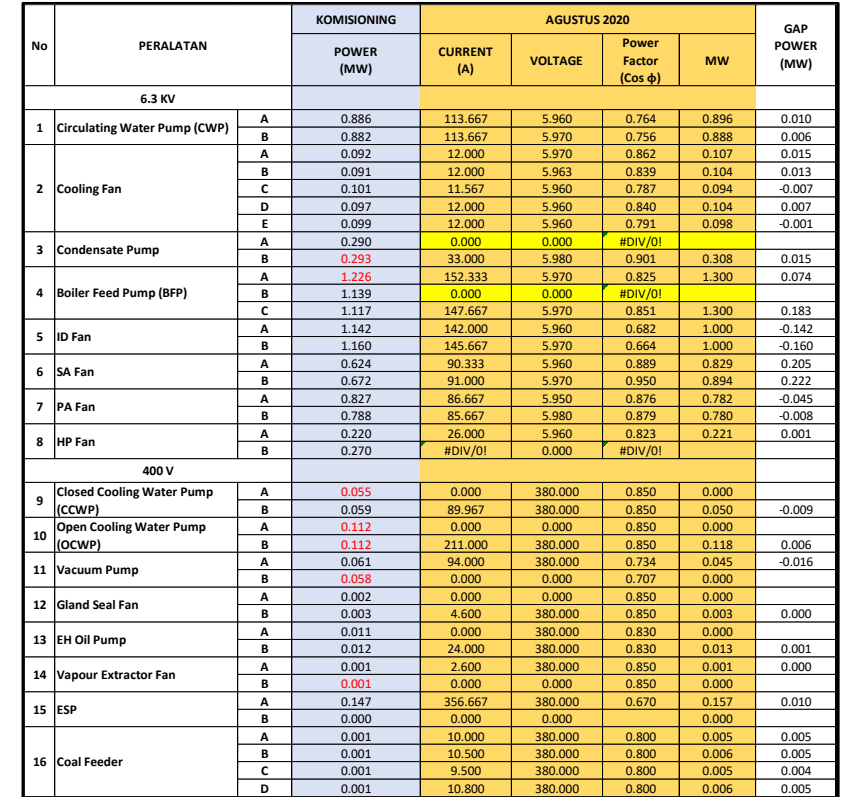

Perubahan konsumsi daya yang bervariasi untuk setiap peralatan, memiliki permasalahan yang berbeda. Dengan melakukan konsep pareto, pembagian loss produksi yang paling besar hingga yang paling kecil dapat dapat dilakukan seperti gambar 3.3.

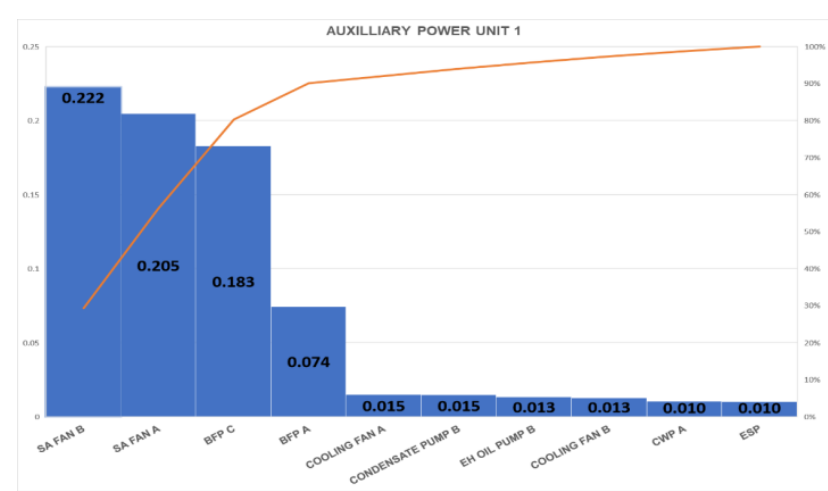

Gambar 3.3. Pareto auxiliary power

Selain memiliki efek terhadap NPHR, meningkatnya konsumsi daya main auxiliary power unit akan menimbulkan loss production seperti yang tertera pada tabel 3.4.

\begin{tabular}{|c|l|c|c|}
\hline No & \multicolumn{1}{|c|}{ Peralatan } & $\begin{array}{c}\text { Loss Power } \\
(\boldsymbol{M W})\end{array}$ & $\begin{array}{c}\text { Loss } \\
\text { Production } \\
(\boldsymbol{R} p \text { /hari })\end{array}$ \\
\hline 1 & Sa Fan B & 0,222 & $7.203 .795,51$ \\
\hline 2 & SA Fan A & 0,204 & $6.625 .819,07$ \\
\hline 3 & BFP C & 0,182 & $5.924 .395,81$ \\
\hline 4 & BFP A & 0,074 & $2.403 .783,73$ \\
\hline
\end{tabular}




\begin{tabular}{|c|l|c|c|}
\hline No & \multicolumn{1}{|c|}{ Peralatan } & $\begin{array}{c}\text { Loss Power } \\
(\text { MW })\end{array}$ & $\begin{array}{c}\text { Loss } \\
\text { Production } \\
\text { (Rp /hari })\end{array}$ \\
\hline 5 & Cooling Fan A & 0,0149 & $483.409,89$ \\
\hline 6 & $\begin{array}{l}\text { Condensate Pump } \\
\text { B }\end{array}$ & 0,0145 & $471.843,48$ \\
\hline 7 & Cooling Fan B & 0,0126 & $408.730,79$ \\
\hline 8 & CWP A & 0,0103 & $335.359,85$ \\
\hline 9 & ESP & 0,0099 & $320.845,95$ \\
\hline \multicolumn{2}{|c|}{ Total Loss production per-hari } & $\mathbf{2 4 , 6 0 2 , 7 6 5 . 8 1}$ \\
\hline
\end{tabular}

\section{Simpulan}

Berdasarkan hasil analisa dapat ditarik beberapa kesimpulan yaitu:

1. NPHR merupakan indikator kehandalan dan efisiensi PLTU. Sebagai indicator kehandalan unit, NPHR dipengaruhi oleh 5 faktor yaitu operator controllable (pengaruh pengoperasian unit), plant controllable (pengaruh siklus produksi), turbine component, boiler component, make up water.

2. Performance test merupakan langkah yang harus dilakukan untuk mengetahui penyebab meningkatnya NPHR serta breakdown permasalahan yang terjadi pada unit PLTU. Besar nilai auxiliary power akan mempengaruhi daya neto yang disuplai oleh PLTU sehingga mempengaruhi nilai $N P H R$ yang dimiliki oleh pembangkit. Meningkatnya nilai auxiliary power sebesar 1,64\% akan meningkatkan NPHR sebesar $55,16 \mathrm{kCal} / \mathrm{kWh}$ dan menjadi losses terbesar pada pareto NPHR.

3. Peningkatan nilai auxiliary power dominan terjadi oleh faktor eksternal yaitu perubahan beban kerja motor listrik akibat adanya kerusakan pada peralatan yang berpengaruh seperti pada SA Fan yang disebabkan karena kebocoran tube air pre-heater dan $B F P$ yang disebabkan oleh kebocoran tube $H P H$. Kerusakan pada beban $B F P$ akan mempengaruhi kinerja condensate pump yang berperan sebagai supplier air deaerator yang merupakan sumber air $B F P$. Vibrasi dan temperatur merupakan 2 faktor internal yang menunjukkan adanya masalah pada peralatan listrik. 2 faktor tersebut akan mempengaruhi kehandalan peralatan saat beroperasi seperti yang terjadi pada motor cooling fan dengan vibrasi $>5$ $\mathrm{mm} / \mathrm{s}$ dan CWP A dengan temperatur $>60{ }^{\circ} \mathrm{C}$. Meningkatnya nilai vibrasi dan temperatur menandakan kerja motor listrik semakin berat

4. Management auxiliary power dengan menggunakan metode mapping pareto auxiliary power merupakan langkah yang harus dilakukan untuk menemukan auxiliary power losses secara tertata dari peringkat tertinggi hingga terendah dan memudahkan untuk menemukan root cause failure peralatan auxiliary dan langkah mitigasi seperti failure defense task (FDT) serta perencanaan yang tepat dalam eksekusi.

\section{Daftar Pustaka}

[1] Nugroho, Agung. 2006. Metode Pengaturan Tenga Listrik Dalam Upaya Penghematan Bahan Bakar Pembangkit dan Energi. Semarang: Jurnal Teknik Elektro - Fakultas Teknik Undip.

[2] Zuhal. 1995. Dasar Teknik Tenaga Listrik dan Elektronika Daya. Jakarta : PT.Gramedia Pustaka Utama.

[3] Kadir, \& dkk. 2020. Analisa Sistem Heat Race Net Plant (NPHR) di NII Tanasa pada Pembangkit Tenaga Uap dengan Kapasitas 2 x 10 MW. Kendari : Jurnal Ilmiah Teknik Mesin

[4] B.L.Theraja, 1988, Electrical Technology Volume II $A C \& D C$ Machines, India : S.chand 